\title{
A comprehensive interpretation of the NEEM basal ice build-up using a multi-parametric approach
}

\author{
Thomas Goossens $^{1}$, Célia J. Sapart ${ }^{1,2}$, Dorthe Dahl-Jensen ${ }^{3}$, Trevor Popp ${ }^{3}$, Saïda El Amri ${ }^{1}$, and Jean-Louis Tison ${ }^{1}$ \\ ${ }^{1}$ Laboratoire de Glaciologie, Université Libre de Bruxelles, 1050 Brussels, Belgium \\ ${ }^{2}$ Institute for Marine and Atmospheric Research Utrecht, Utrecht University, 3584CC Utrecht, the Netherlands \\ ${ }^{3}$ Centre for Ice and Climate, Niels Bohr Institute, University of Copenhagen, 2100 Copenhagen, Denmark
}

Correspondence to: Jean-Louis Tison (jtison@ulb.ac.be)

Received: 8 July 2015 - Published in The Cryosphere Discuss.: 19 October 2015

Revised: 2 February 2016 - Accepted: 11 February 2016 - Published: 9 March 2016

\begin{abstract}
Basal ice is a common expression to describe bottom ice layers of glaciers, ice caps and ice sheets in which the ice is primarily conditioned by processes operating at the bed. It is chemically and/or physically distinct from the ice above and can be characterized by a component of basally derived sediments. The study of basal ice properties provides a rare opportunity to improve our understanding of subglacial environments and processes and to refine ice sheet behaviour modelling. Here, we present and discuss the results of water stable isotopes $\left(\delta^{18} \mathrm{O}\right.$ and $\left.\delta \mathrm{D}\right)$, ice fabrics, debris weight/size distribution and gas content of the basal part of the NEEM (North Greenland Eemian Ice Drilling Project) ice core. Below a depth of $2533.85 \mathrm{~m}$, almost $10 \mathrm{~m}$ of basal debris-rich material was retrieved from the borehole, and regular occurrence of frozen sediments with only interstitial ice lenses in the bottom $5 \mathrm{~m}$ suggest that the ice-bedrock interface was reached. The sequence is composed of an alternation of three visually contrasting types of ice: clear ice with specks (very small amounts) of particulate inclusions, stratified debrisrich layers and ice containing dispersed debris. The use of water stable isotope signatures $\left(\delta^{18} \mathrm{O}\right.$ and $\left.\delta \mathrm{D}\right)$, together with other parameters, allows discrimination between the different types of ice and to unravel the processes involved in their formation and transformation. The basal debris-rich material presents $\delta^{18} \mathrm{O}$ values $[-39.9 \%$; $-34.4 \%$ o] within the range of the above last $300 \mathrm{~m}$ of unaltered meteoric ice [-44.9\%; $-30.6 \%$ o] spanning a glacial-interglacial range of values. This rules out the hypothesis of a basal ice layer originating from pre-ice sheet ice overridden by the growing ice sheet, as previously suggested e.g. in the case of GRIP (Greenland Ice Core Project). We show that clear basal ice with specks
\end{abstract}

corresponds to altered meteoric glacial ice where some of the climatic signal could have been preserved. However, the stratified debris-rich layers and the ice containing dispersed debris layers respectively express an "open" or "closed" system melting/refreezing signature, somewhat blurred by mixing processes in the upper part of the sequence. Climatic reconstruction is therefore prohibited from these ice types. We propose a first interpretative framework for the build-up of the NEEM basal ice sequence, based on the origin of the various ice types.

\section{Introduction}

The dynamics of ice sheets and their climatic feedback and future contribution to sea level rise still remains highly uncertain (Church et al., 2013). Establishing more accurate and constrained models of ice sheet behaviour has therefore become an important scientific challenge.

The basal ice layer (BIL) of an ice sheet is primarily conditioned by processes operating at the bed and often contains debris-laden ice close to the ice-bedrock interface (Souchez et al., 1978). It is, according to the following description (Knight, 1997), "a rheological control on ice sheet dynamics; an indicator of subglacial conditions and processes; a limit to the downward extension of climate record from deep ice core(s)". Because its physical and chemical characteristics are representative of the different processes leading to its formation, a multi-parametric study of the BIL offers the opportunity to infer the former thermal, rheological and environmental conditions prevailing during its formation and re- 
veals the processes acting at the ice-bedrock interface (Hubbard and Sharp, 1995; Alley et al., 1998; Lawson et al., 1998; Christoffersen and Tulaczyk, 2003; Christoffersen et al., 2006; Cook et al., 2007; Hubbard et al., 2009). These inferences allow the establishment of better constrained initial and boundary conditions required for ice sheet modelling and bound the validity of paleoclimatic data interpretation.

Understanding basal ice processes is therefore an important challenge to face for those who are looking at ice older than a million years in Antarctica or trying to decipher the details of rapid climate changes in more recent times in Greenland (Fischer et al., 2013).

To date, only a few deep ice core projects have been conducted on the Greenland main ice divide (Dye3 - ice core locations elected at one of the 58 US radar stations of the Distant Early Warning Line; GISP2 - Greenland Ice Sheet Project; GRIP - Greenland Ice Core Project; NGRIP - NorthGRIP), most recently NEEM. Due to difficulties in accessing the bedrock, the various processes involved in the formation of a BIL and their possible interactions are still not well understood. Previous studies summarised in two review papers (Hubbard and Sharp, 1989; Knight, 1997) have, however, identified a certain number of mechanisms leading to a physically distinguishable BIL.

Basal temperature below the pressure melting point (pmp) allows the formation and preservation of a basal ice sequence as recovered for example from the Byrd (Antarctica) and GRIP and GISP2 ice core (Gow and Meese, 1996). In other areas where the pmp is reached, paleoclimatic information could be partially melted away and lost e.g. at NGRIP (Andersen et al., 2004). In any case, interactions between moving ice and the irregular bedrock can result in flow disturbances, partial alteration of the ice properties and a loss of climate and environmental signal much higher into the ice column and well above the BIL (e.g. Landais et al., 2012; Tison et al., 2015).

The international NEEM project aimed to recover a complete and unaltered sequence of Eemian ice and it succeeded to reach close to the bedrock in 2011 at a depth of $2537.980 \mathrm{~m}$. About $4 \mathrm{~m}$ of debris-rich ice was retrieved at that time (Dahl-Jensen et al., 2013). During the 2011 and 2012 field seasons, a narrower borehole was drilled further through about $6 \mathrm{~m}$ of frozen sediment layers alternating with sparser clear ice segments containing dispersed debris (IDD). This is the second time that a complete sequence from nonaltered ice originating from a firnification process (referred to here as meteoric ice - MI) to frozen sediments has been retrieved from a borehole in central Greenland (first time being the GISP2 ice core; Gow and Meese, 1996).

In this paper, we use a high-resolution multiparametric approach (stable isotopes, ice fabrics, debris content and total gas content) to achieve a comprehensive interpretation of the NEEM basal ice build-up. We follow here the terminology proposed by Tison et al. (2015), in which "basal ice" practically refers to the part of the ice core showing visible solid inclusions. This is also because the sampling protocol for the NEEM ice core needed some visual criteria to adapt the sampling scheme. In this study the presence of millimetric solid inclusions in the BIL is shown to be an indicator of a transformation process resulting from interaction with the bedrock, but it does not necessary mean that these inclusions originated from the ice bedrock interface. The term "deep ice" is used to name the ice sequence just above, which is potentially altered by the vicinity of the bedrock but does not show any visible inclusions.

\section{Material and methods}

\subsection{Drilling}

The NEEM core $\left(77.45^{\circ} \mathrm{N}, 51.06^{\circ} \mathrm{W}\right)$ was drilled between 2008 and 2012 field seasons using the Hans Tausen (HT) drill (9.8 $\mathrm{cm}$ inner diameter) (Johnsen et al., 2007) from the surface to the depth of $2537.990 \mathrm{~m}$. Because of the increasing occurrence of solid particles with depth, a narrower dedicated "rock drill" (RD) (2.5 cm inner diameter) was used below this depth and the final depth of $2543.840 \mathrm{~m}$ was reached. For transport and storage purposes the core was cut into $55 \mathrm{~cm}$ sub-units called "bags".

\subsection{Sampling and analytical methods}

The basal ice layer, as defined in the introduction, starts effectively at bag 4595, corresponding to a depth of $2527.250 \mathrm{~m}$. However, because visible solid inclusions were only described in the field starting at $2533.85 \mathrm{~m}$ depth, for logistic reasons, the NEEM community has only adopted the dedicated basal sampling procedure (defining the dimensions of samples attributed to each measurement) from that depth (bag 4608) onwards, the segment which is the focus of the present study. Samples were cut using a Well 6234 diamond wire saw (Tison, 1994). Due to its smaller diameter $(2.5 \mathrm{~cm})$ the basal cutting scheme was not applied to the RD core for which a smaller number of parameters are possibly extractable.

The total gas content (TGC) was measured using a Toepler pump and the melting/refreezing $(M / R)$ extraction technique (Martinerie et al., 1994; Raynaud et al., 1983). The existence of numerous debris layers is a potential indicator of the occurrence of $M / R$ events (Hubbard and Sharp, 1989; Knight, $1997)$ that lead to a drastic depletion of the gas content. In order to insure detectable measurements, samples of $5 \mathrm{~cm}$ vertical resolution were measured by groups of three or four. Data are expressed in millilitres of gas per kilogram of ice $\left(\mathrm{mL}_{\text {gas }} \mathrm{kg}_{\mathrm{ice}}^{-1}\right)$ and the precision is estimated at $\pm 5 \%$.

Melted residues from TGC samples were filtered on $0.20 \mu \mathrm{m}$ Millipore $^{\circledR}$ filters. Collected dry residues were weighed and their content expressed as weight percentage of the ice plus debris weight. Note that the sampling resolution of debris content is therefore inherited from the TGC samples grouping. 
Ice water isotopes were measured at the Niels Bohr Institute - Center for Ice and Climate, Copenhagen - using a Picarro 2120 cavity ring-down spectroscopy analyser equipped with a high throughout evaporator. Data are expressed as per mille $(\%)$ difference relative to Vienna Standard Mean Ocean Water (VSMOW) and the accuracy is $0.01 \%$ for both $\delta \mathrm{D}$ and $\delta^{18} \mathrm{O}$. The initial vertical resolution was $5 \mathrm{~cm}$ for the first series of samples corresponding to the ice drilled during the 2010 field season (2533.850-2537.300 m depth). To ensure a better detection of potential small-scale $M / R$ events, the samples covering the 2011 and 2012 field season (below $2537.300 \mathrm{~m}$ ) were later analysed at $2 \mathrm{~cm}$ vertical resolution.

In order to cope with the presence of debris, vertical 400 microns thin sections were prepared (resolution $5 \mathrm{~cm}$ ) using a Well 6234 diamond wire saw (Tison, 1994) instead of the standard microtome procedure initially described in Langway (1958). $C$ axis orientations were obtained using a G50 Fabric Analyser (Wilson et al., 2003). The analyser generates a file containing lines of raw orientation information with quality factors at the pixel scale $(1$ pixel $=43 \mu \mathrm{m})$. This raw data set was post-processed using algorithms from the MTEX (Bachmann et al., 2010) and FAME (Peternell et al., 2014) MATLAB ${ }^{\circledR}$ toolboxes in order to filter the poor-quality pixels (threshold: quality parameter lower than $70 \%$ ) and produce stereographic pole plots in the vertical plane. The size of the crystals is revealed by pictures of cross-polarised thin sections generated by the fabric analyser.

Granulometry of the incorporated debris was measured on discrete selected samples using a Malverner Mastersizer $3000^{\circledR}$ laser granulometer.

\section{Results}

\subsection{Ice types and debris content}

Figure 1 displays representative samples of our classification based on the raw visual appearance of the ice types encountered in the NEEM basal ice sequence.

As described in Sect. 2, a specific cutting procedure has been adopted from the first core encountered showing conspicuous layers of highly concentrated debris (top at $2533.850 \mathrm{~m}$ ), following a "practical" definition of the basal ice layer. However, it was discovered "a posteriori" that the first visible solid inclusions occur further up in the core at a depth of $2527.250 \mathrm{~m}$. These start as scarce (a few per $55 \mathrm{~cm}$ "bag" core) submillimetric pinhead like inclusions, with their size and densities slowly increasing downwards. We will refer to this ice type illustrated in Fig. 1a, as "clear ice with specks" (CIS; white symbols in Fig. 2a). It would correspond to the lower end (in terms of debris concentration) of the banded dispersed cryofacies of Hubbard et al. (2009).

From 2533.850 to $2536.600 \mathrm{~m}$ (Fig. 2a), the BIL is dominated by this ice type showing increasingly large amount of very small dark solid inclusions. The diameters of these specks range between less than $1 \mathrm{~mm}$ in the top and up to

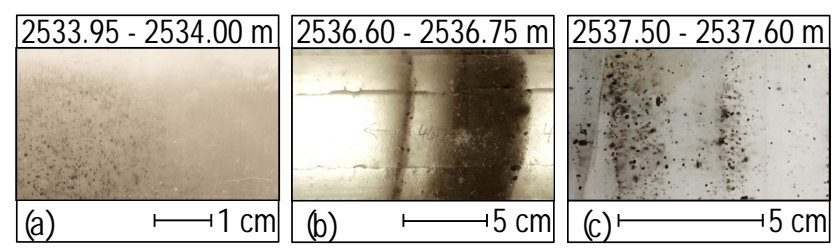

Figure 1. Representative photographs of the three visually contrasting ice types encountered in the NEEM BIL sampled with the HT drill: (a) clear ice with specks (CIS), (b) debris-rich layers (DRL) embedded in clear ice and (c) ice containing dispersed debris (IDD). Note the difference in scales for the three pictures.

$3 \mathrm{~mm}$ downcore. Figure 3 shows the volume (in \%) and cumulated volume (in \%) for the range of size from clays to gravels for a set of representative samples from the NEEM BIL. CIS (Fig. 3a) mainly consists of silts (local maximum at $40 \mu \mathrm{m}$ ) and small sands (local maximum at $150 \mu \mathrm{m}$ ), which suggests that most of the specks actually consist of aggregates of individual particles.

Embedded in this CIS, segments of ice containing individual high-concentration debris layers (second ice type, Fig. 1b, black symbols in Fig. 2a, ranging from 2 to $5 \mathrm{~mm}$ in thickness) were observed at depths from 2534.500 to 2534.600 and from 2534.850 to $2534.870 \mathrm{~m}$. In these highconcentration debris-rich layers (DRL), debris size ranges from clay to coarse sand and fine gravels (Fig. 3b) and the debris weight content reaches $0.4 \%$ (at $20 \mathrm{~cm}$ depth resolution - Fig. 2b).

A similar sequence, but with much larger DRL segments (from 1 to $12 \mathrm{~cm}$ in thickness), is observed between 2536.600 and $2538.145 \mathrm{~m}$ (Figs. 1b, 2a). In some of these layers, the debris weight content peaks at $23 \%$ (Fig. 2b) (at $15 \mathrm{~cm}$ depth resolution) and the debris size distribution resembles the one in the DRL above, with a large proportion of fine sands (Fig. 3c). In one of these layers at $2536.650 \mathrm{~m}$ depth, a large granite pebble of $5 \mathrm{~cm}$ of diameter is protruding from the side of the core. A careful examination of these DRL segments (e.g. Fig. 1b) shows that they generally consist of an alternation of thinner individual debris layers with clear ice laminae. This is typical of what has been referred to as the laminated cryofacies in Hubbard et al. (2009) classification of basal ice types.

At $2537.300 \mathrm{~m}$ depth, a new ice type can be observed (Fig. 1c and grey symbols in Fig. 2a) that consists of clear IDD at such low concentration (typically 0.5 to a few $\%$ in weight) that the ice still remains transparent. Individual debris particles are roughly aligned in laminated bands that occasionally cross-cut at low angles, suggesting a folding structure (Fig. 1c). This ice type could also be classified as a banded dispersed cryofacies with a higher debris content than the CIS described above. 


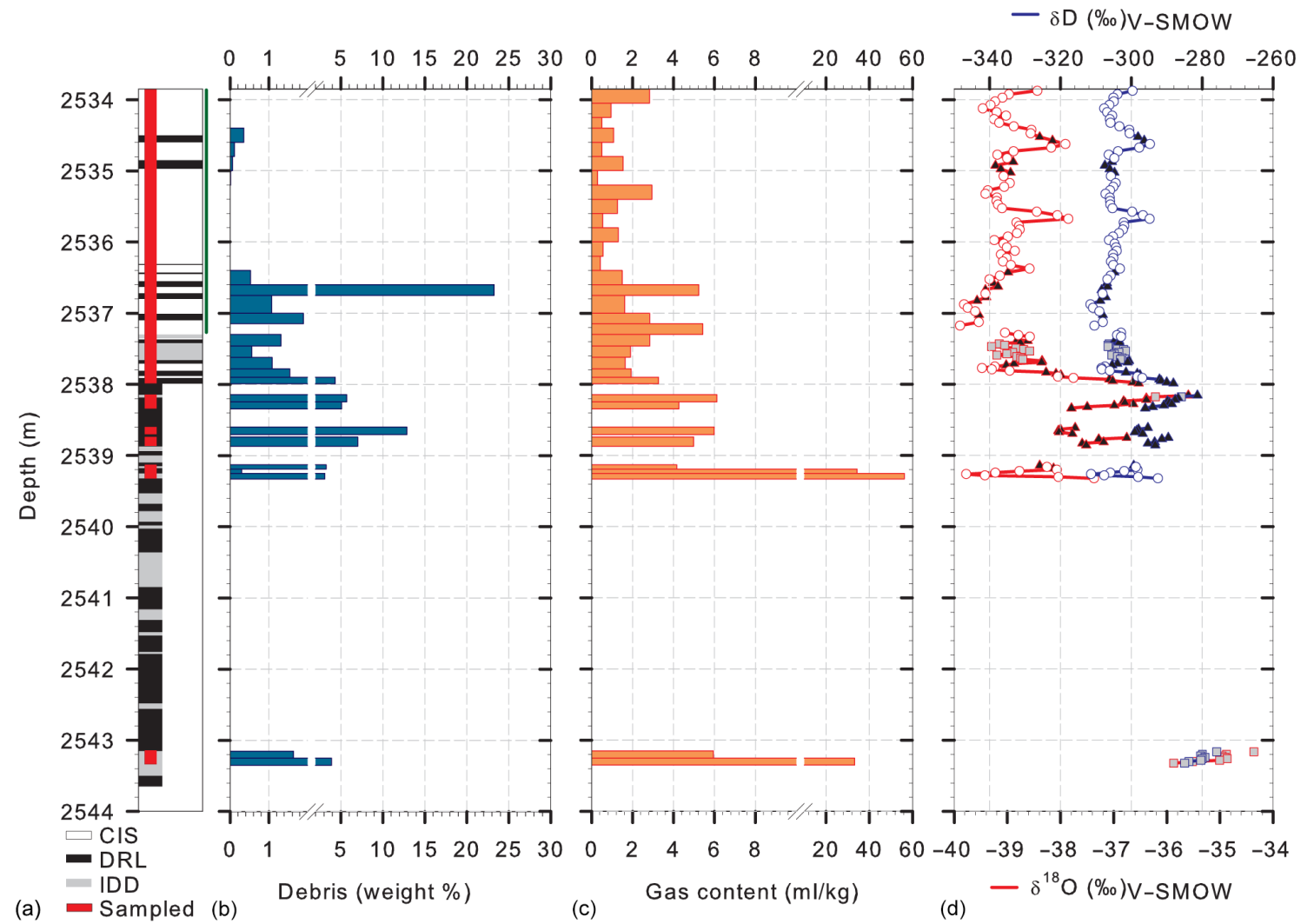

Figure 2. Vertical profiles: (a) symbolic representation of the ice types encountered along the core (CIS, DRL, IDD). The green bar corresponds to the part of the core detailed in Fig. 4, (b) debris content in weight percentage, (c) total gas content in $\mathrm{mLgas}_{\mathrm{gg}}^{-1}$, (d) $\delta^{18} \mathrm{O}$ (bottom axis, red symbols) and $\delta \mathrm{D}$ (top axis, blue symbols); white circles indicate CIS; black triangles are DRL; grey squares are IDD.
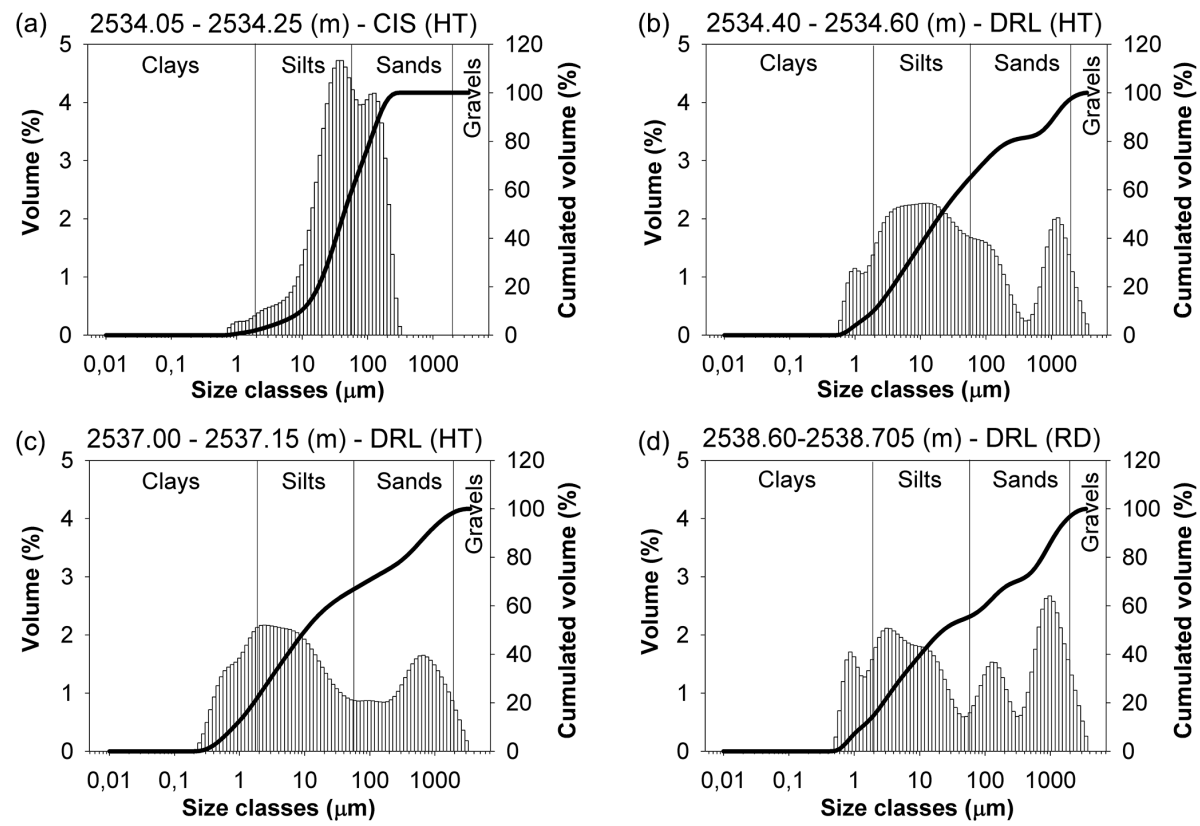

Figure 3. Granulometric plots for characteristic samples at increasing depths. Grey vertical bars indicate volume (\%) and the black line cumulative volumes (\%). 


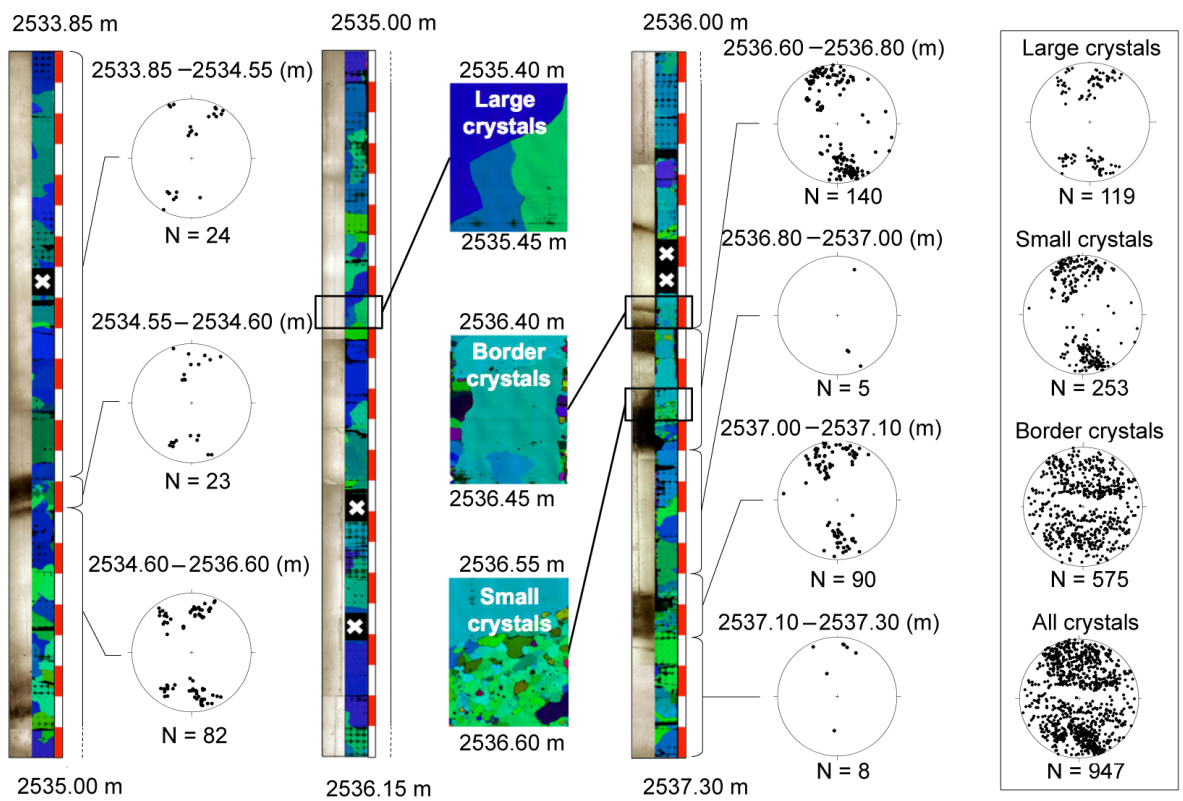

Figure 4. Vertical profile presenting the 2011 season HT drill cores. From left to right, for each section of the core: photographs of the core in transmitted light, vertical thin sections images from the automated ice fabric analyser and fabric plots in the vertical plane with associated depth range for the crystals used. The red and white scale units are $5 \mathrm{~cm}$ each. The frame presents the fabrics for crystals grouped by types.

Along the same lines the DRL segments show evidence of tilting with regard to the core axis (the "vertical") and that the dip goes in opposite directions depending on the section considered in the BIL (Fig. 4, left vertical strip showing core in transmitted light). This observation is valid since the azimuth of the core remains coherent throughout the BIL.

Down to the depth of $2541.800 \mathrm{~m}$, clear ice layers containing variable amount of dispersed debris alternate with more frequent layers of ice presenting high-concentration debris layers (Fig. 2a). Below that depth the core mainly consists of an alternation of unsorted frozen sediments layers, the solid cryofacies in Hubbard et al. (2009) and ice layers with dispersed debris (also referred to as IDD). In this section, the debris size range is similar to the DRL above with further increase of the small sand proportion (Fig. 3d). Pebbles of centimetre size are regularly found in this lower part of the basal ice sequence. An irregular increasing downward trend in debris content (Fig. 2b) and debris size (Fig. 3) is observed along the NEEM basal ice core.

\subsection{Gas content}

The TGC vs. depth profile of the NEEM BIL shows a generally increasing trend from the top to the bottom of the sequence (Fig. 2c). The lowest value $\left(0.30 \mathrm{~mL}_{\mathrm{gas}} \mathrm{kg}_{\text {ice }}^{-1}\right)$ is observed in the upper part of the core where the TGC is quite constant around $1 \mathrm{~mL}_{\text {gas }} \mathrm{kg}_{\text {ice }}^{-1}$ (from 2533.850 to $2536.600 \mathrm{~m})$.

At intermediate depths (2536.600-2539.190 m), the TGC is more variable with slightly higher values fluctuating around $4 \mathrm{~mL}_{\text {gas }} \mathrm{kg}_{\text {ice }}^{-1}$. The lowest part of the core is characterized by TGC up to 5 times higher than measured in the upper layers and reaches a maximum observed value of $56.17 \mathrm{~mL}_{\text {gas }} \mathrm{kg}_{\text {ice }}^{-1}$ at $2539.250 \mathrm{~m}$ of depth.

Close to the bottom, the TGC is similar to the one at intermediate depth. The deepest sample $(2543.250 \mathrm{~m})$ reaches a second maximum of $33.25 \mathrm{~mL}_{\mathrm{gas}} \mathrm{kg}_{\text {ice }}^{-1}$.

The mean TGC value of the entire NEEM BIL $\left(6.19 \mathrm{~mL}_{\text {gas }} \mathrm{kg}_{\text {ice }}^{-1}\right)$ is very low compared to the typical dryfirn derived MI value of about $90 \mathrm{~mL}_{\text {gas }} \mathrm{kg}_{\text {ice }}^{-1}$ (Martinerie et al., 1994; Raynaud et al., 1983).

\subsection{Stable isotope composition}

The depth profiles of the ice-water isotopes of the NEEM basal ice core are shown in Fig. $2 \mathrm{~d}$ with $\delta \mathrm{D}$ and $\delta^{18} \mathrm{O}$ expressed in per mille (\%o) vs. the VSMOW. The various symbols in Fig. 2d refer to the different visual ice types identified above with CIS as white circles, DRL as black triangles and IDD as grey squares.

With a mean value of $-38.4 \%$, the $\delta^{18} \mathrm{O}$ profile displays a non-linear downward trend towards an isotopic enrichment in heavy isotopes (i.e. increasing $\delta$ values).

Along the first $2.8 \mathrm{~m}$ of the core where $5 \mathrm{~cm}$ resolution measurements were performed, $\delta^{18} \mathrm{O}$ values slightly fluctuate around $-39.0 \%$ with two layers enriched by about $1 \%$ in heavy isotopes at 2534.600 and $2535.650 \mathrm{~m}$ depth.

From 2536.600 to $2537.150 \mathrm{~m}$, the ice shows a progressive depletion in heavy isotopes and reaches the lowest value measured in $\delta^{18} \mathrm{O}(-39.9 \%$ ) at $2537.150 \mathrm{~m}$ of depth. 
Between 2537.150 and $2537.900 \mathrm{~m}$, the $\delta^{18} \mathrm{O}$ profile is nearly constant and its values are again clustered around $-39.0 \%$.

From $2537.900 \mathrm{~m}$ depth to $2539.310 \mathrm{~m}$, the $\delta^{18} \mathrm{O}$ profile shows a positive trend towards isotopic enrichment and larger amplitude variations with a difference of about $3.5 \%$ between the lowest value $(-39.9 \%$ ) and the locally most enriched layer $(-35.5 \%$ ) respectively at 2537.175 and $2538.145 \mathrm{~m}$ depth.

Finally, the deepest samples (below $2543.150 \mathrm{~m}$ ) are characterized by the highest $\delta^{18} \mathrm{O}$ values recorded in the NEEM BIL with a maximum of $-34.4 \%$. These remain well in the range of $\delta^{18} \mathrm{O}$ values observed in the ice above the BIL (last $300 \mathrm{~m}$ depth interval above the BIL, Fig. 5, dark crosses).

The $\delta \mathrm{D}$ profile follows the same pattern as the $\delta^{18} \mathrm{O}$ with a mean value of $-301 \%$ and it ranges from $-311 \%$ (at $2536.850 \mathrm{~m}$ depth) to $-275 \%$ (at $2543.150 \mathrm{~m}$ depth).

\subsection{Ice textures and fabrics}

Textures and fabrics have only been investigated on the basal ice sequence drilled during the 2010 field season, which represents $3.45 \mathrm{~m}$ of material represented by the green line on the right of Fig. 2a. A detailed view of this sequence is presented in Fig. 4.

Large interlocking crystals (up to $15 \mathrm{~cm}$ equivalent diameter) are representative of clear ice layers while small crystals (less than $1 \mathrm{~cm}$ equivalent diameter) are always found in the debris layers.

As shown by the $c$ axis pole diagrams (summarised in the last column of Fig. 4) the two types of ice crystals show strikingly different fabrics. Large crystals are organised in such a way that their fabric shows a small girdle roughly centred around the core axis, while small crystals plot as a single maximum along the same direction. Surprisingly, a third type of generally small crystals frequently occurs along the sides of the ice core (e.g. see thin section at a depth of $2536.400 \mathrm{~m}$ in Fig. 4). The fabric of these border crystals partly mimics the pattern of the populations of small and large crystals but also add randomness to the distribution. Note that these border crystals are part of the ice core and do not represent the expression of "water welding" during the thin sectioning procedure.

\section{Discussion}

During ice formation the basal sequence has lost an important part of its gas content and contains numerous debris layers. This study is based on a co-isotopic approach in order to test whether processes involving $M / R$ events, able to reject gases and incorporate the coarser particles in the observed debris range, could be responsible for the build-up of the sequence or at least parts of it.
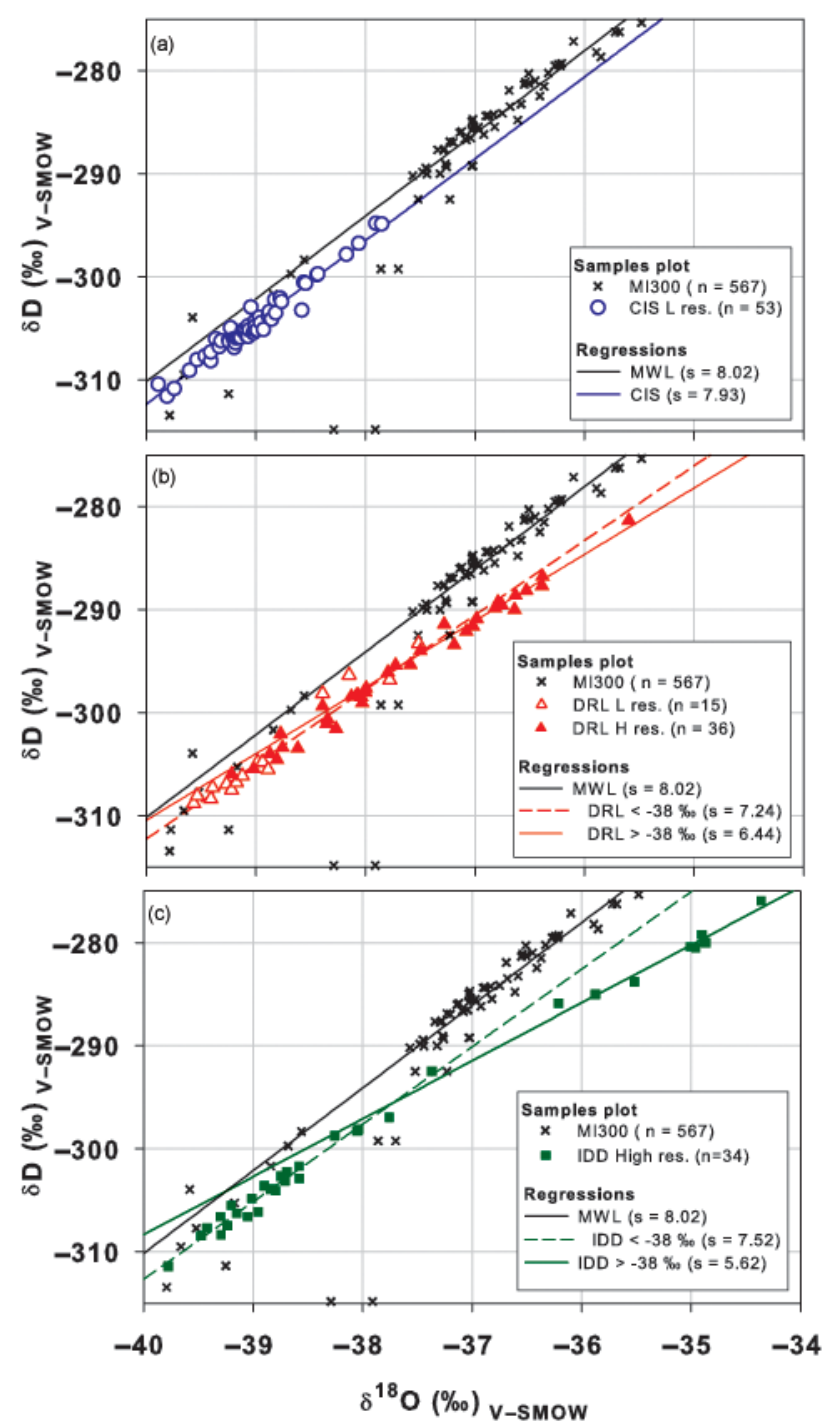

Figure 5. Co-isotopic diagram presenting both the last $300 \mathrm{~m}$ of meteoric ice (MI300) and the basal ice samples at the NEEM location. The plot is centred on the BIL range. Open symbols correspond to low vertical resolution samples $(5 \mathrm{~cm})$ and closed symbols to high vertical resolution samples $(2 \mathrm{~cm})$. Lines are regressions for investigated groups of samples; $n$ is the number of samples of the considered group; $s$ is the value of the slope of the regressions.

\subsection{A $\delta^{18} \mathrm{O}_{\text {ice }}-\delta \mathrm{D}_{\text {ice }}$ approach to detect melting/refreezing processes}

Figure 5 shows the $\delta^{18} \mathrm{O}_{\text {ice }}-\delta \mathrm{D}_{\text {ice }}$ relationship for the various ice types described in Sect. 3.1 and compares it to the coisotopic signature of the 567 samples of MI from the $300 \mathrm{~m}$ above (black crosses). Samples of MI are aligned on a slope of 8.02 which is typical of the global meteoric water line (MWL) (Craig, 1961). 


\subsubsection{The "freezing slope" concept and caveats}

On a co-isotopic diagram, a $M / R$ process can be detected by a slope of the $\delta^{18} \mathrm{O}_{\text {ice }}-\delta \mathrm{D}_{\text {ice }}$ relationship for a group of samples significantly lower than 8 , in accordance with what is usually referred to as a "freezing slope". A freezing slope is the result of a fractionation effect between light and heavy isotopes in the course of freezing. Jouzel and Souchez (1982) have theoretically computed the value of the freezing slope in the case of a closed system reservoir $\left(S_{\mathrm{cs}}\right)$ and successfully validated it on an experimental setup (Souchez and Jouzel, 1984). It is expressed as

$S_{\mathrm{cs}}=\frac{(\alpha-1)\left(1000+\delta \mathrm{D}_{\mathrm{res}}\right)}{(\beta-1)\left(1000+\delta^{18} \mathrm{O}_{\mathrm{res}}\right)}$,

where $\alpha(=1.0212)$ and $\beta(=1.00291)$ are the equilibrium fractionation coefficients between water and ice for $\mathrm{D} / \mathrm{H}$ and ${ }^{18} \mathrm{O} /{ }^{16} \mathrm{O}$ respectively (Lehmann and Siegenthaler, 1991) and $\delta^{18} \mathrm{O}_{\text {res }}$ and $\delta \mathrm{D}_{\text {res }}$ are the initial isotopic composition of the reservoir before freezing. In the basal part of an ice sheet, the meltwater supplying a freezing reservoir most presumably originates from the meteoric ice above. As no isotopic fractionation occurs during melting (Friedman et al., 1964; Souchez and Lorrain, 1991), $\delta^{18} \mathrm{O}_{\text {res }}$ and $\delta \mathrm{D}_{\text {res }}$ are located on the MWL, i.e. at the intersection with the best fit line across the samples resulting from the freezing process.

Several studies have used this concept of the "freezing slope" to track $M / R$ processes in basal ice sequences of ice sheets (Knight, 1989; Hubbard and Sharp, 1993, 1995; Iverson and Souchez, 1996; Souchez et al., 1988, 1994, 1998; Cook et al., 2009; Larson et al., 2010) by comparing the $\delta^{18} \mathrm{O}_{\text {ice }}-\delta \mathrm{D}_{\text {ice }}$ regression line of their set of samples to the modelled freezing line, using closed system Eq. (1) with the initial values for the freezing meltwater provided by the intersection of the $\delta^{18} \mathrm{O}_{\text {ice }}-\delta \mathrm{D}_{\text {ice }}$ regression line through the samples with the MWL. These attempts were only partly successful due to various potential sources of bias summarised below and in Fig. 6:

a. The vertical sampling resolution may affect the detection of a $M / R$ signature. To pinpoint any isotopic fractionation in a sample, its vertical size must be smaller than the one of the refreezing process (Souchez et al., 1988). If a single sample covers the full set of refreezing increments, its measured $\delta$ value corresponds to the average $\delta$ value of all the increments together. Because this average is equal to the meteoric $\delta$ value of the initial reservoir admitted to freeze $\left(\delta^{18} \mathrm{O}_{\text {res }}\right.$ and $\left.\delta \mathrm{D}_{\text {res }}\right)$, no isotopic fractionation is detected (Fig. 6, case a).

b. Equation (1) is only valid for "closed system" freezing. In nature, it is possible that the system is "open" both in terms of refrozen ice/meltwater ratio and in terms of the water isotopic signature. This more complex case has been discussed (Souchez and De Groote, 1985; Souchez and Jouzel, 1984) and provides the following expression for the "open system" freezing slope $S_{\mathrm{OS}}$ (Fig. 6, case b):

$S_{\mathrm{OS}}=\frac{\alpha(\alpha-1)\left(1000+\delta \mathrm{D}_{\mathrm{res}}\right)-\frac{\mathrm{A}}{\mathrm{F}}\left(\delta \mathrm{D}_{\text {inp }}-\delta \mathrm{D}_{\mathrm{res}}\right)}{\beta(\beta-1)\left(1000+\delta^{18} \mathrm{O}_{\mathrm{res}}\right)-\frac{\mathrm{A}}{\mathrm{F}}\left(\delta^{18} \mathrm{O}_{\text {inp }}-\delta^{18} \mathrm{O}_{\mathrm{res}}\right)}$,

where $\delta^{18} \mathrm{O}_{\text {res }}$ and $\delta \mathrm{D}_{\text {res }}$ are the isotopic composition of the water reservoir before freezing and $\delta^{18} \mathrm{O}_{\text {inp }}$ and $\delta \mathrm{D}_{\text {inp }}$ are the isotopic composition (considered constant) of the input water joining the reservoir in the course of freezing. $A$ and $F$ are respectively the constant input and freezing rate. While the closed system approach provides a single theoretical freezing slope, the open system model usually provides a set of multiple possible freezing slopes, the range of which is constrained by generally unknown values of $\delta_{\text {inp }}$ and $A / F$. Given the numerous possible freezing slopes it provides, the open system approach increases the probability of finding a fit that describes sufficiently the observations, making it a less parsimonious model. The sensitivity of the basal ice isotopic signature to the range of isotopic values of the input water and to the "degree of closure" of the system (ratio $A / F$ ) has been discussed in previous modelling exercises (Hubbard and Sharp, 1995; Cook et al., 2009). The authors concluded that a freezing slope might not be displayed, and they suggested that only a range of plausible values for the input waters can be deduced from the observed isotopic signature of the ice.

c. If the vertical sampling resolution is too coarse, it could also possibly lead to measurements that mix both $M / R$ and meteoric signals. In such situations, samples might be located on intermediate positions between the MWL and the freezing line, their precise coordinates depending on both the proportion and values of each of the co-isotopic signals they combine. Such a process has a higher probability to result in a more scattered distribution between theoretical freezing slopes and the MWL (Fig. 6, case c). A similar case could be drawn for a mixing process with a "closed system" freezing slope.

\subsubsection{Tracking $M / R$ in the NEEM basal ice}

In the following sections, we will use analyses of covariance techniques (ANCOVA), to track $M / R$ processes in our various ice types from the NEEM basal ice. The rationale is as follows: for each group of observations, a regression line is calculated with slope $S_{\text {obs }}$ (Table 1a). At first, $S_{\text {obs }}$ is compared to the slope of the MWL ( $S_{\mathrm{MWL}}$ ). The $M / R$ origin hypothesis is refuted if both slopes are not significantly different ( $P$ value $>0.01)$. However, if $S_{\text {obs }}$ is significantly lower than $S_{\mathrm{MWL}}(P$ value $\leq 0.01)$, the considered group of samples could presumably originate from a $M / R$ process. This assumption is further tested by comparing $S_{\text {obs }}$ with the expected closed system slope $\left(S_{\mathrm{cs}}\right)$ computed from Eq. (1) with 


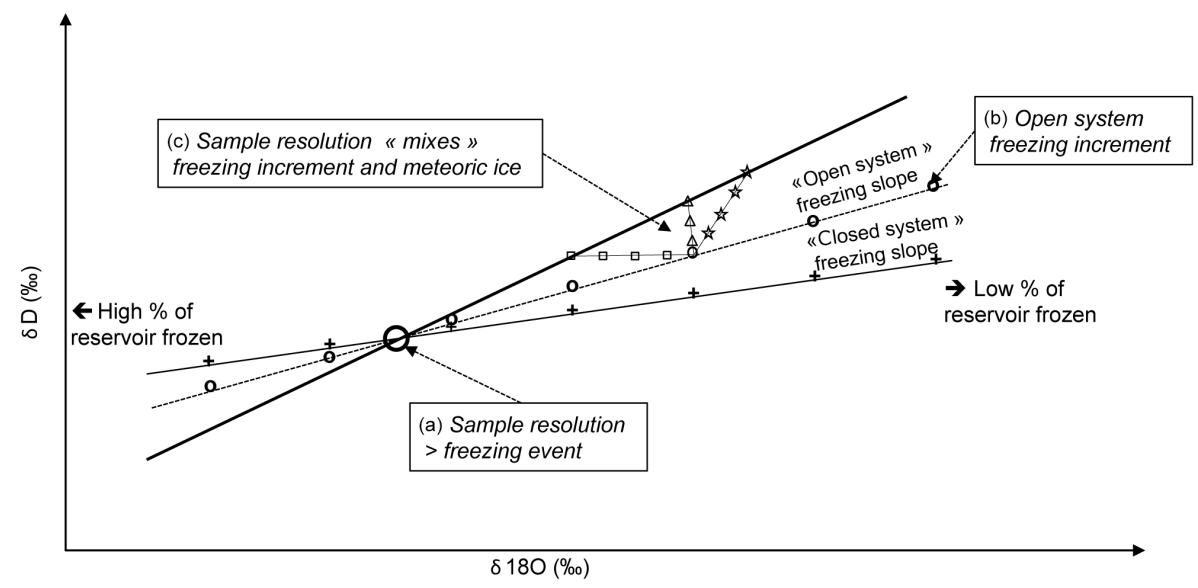

Figure 6. Scheme describing the potential isotopic signatures for various combinations of open and closed system freezing, mixing and sampling resolution. The black thick line represents the meteoric water line.

Table 1. (a) Parameters of regressions and (b) theoretical slopes computed using the closed system model Eq. (1).

\begin{tabular}{|c|c|c|c|c|}
\hline \multicolumn{5}{|l|}{ (a) Observed regression line } \\
\hline Group of samples & Acronym & Slope $\left(S_{\text {obs }}\right)$ & Intercept & $R^{2}$ \\
\hline Meteoric ice from $300 \mathrm{~m}$ above the basal ice layer & MI300 & 8.02 & 10.73 & 0.99 \\
\hline Whole basal ice sequence & $\mathrm{BI}_{\text {whole }}$ & 6.48 & -51.99 & 0.98 \\
\hline Clear ice with specks & CIS & 7.93 & 4.95 & 0.96 \\
\hline Debris-bearing ice (DRL + IDD) & DB & 6.47 & -52.57 & 0.99 \\
\hline Debris-rich layers & DRL & 6.91 & -35.60 & 0.98 \\
\hline Ice with dispersed debris & IDD & 6.27 & -60.31 & 0.99 \\
\hline Debris-rich layers, $\delta^{18} \mathrm{O}>-38 \%$ o & $\mathrm{DRL}>38$ & 6.45 & -52.61 & 0.97 \\
\hline Debris-rich layers, $\delta^{18} \mathrm{O}<-38 \%$ o & $\mathrm{DRL}<38$ & 7.24 & -22.77 & 0.94 \\
\hline Ice with dispersed debris, $\delta^{18} \mathrm{O}>-38 \%$ o & IDD $>38$ & 5.62 & -83.40 & 0.99 \\
\hline Ice with dispersed debris, $\delta^{18} \mathrm{O}<-38 \%$ o & IDD $<38$ & 7.52 & -11.79 & 0.96 \\
\hline \multicolumn{5}{|l|}{ (b) Theoretical closed system freezing line } \\
\hline $\begin{array}{l}\text { Initial water used for slope calculation } \\
(\cap=\text { intersection) }\end{array}$ & $\delta^{18} \mathrm{O}$ intercept & $\delta \mathrm{D}$ intercept & $\begin{array}{l}\text { Theoretical } \\
\text { slope }\left(S_{\mathrm{cs}}\right)\end{array}$ & $\begin{array}{r}\text { Theoretical } \\
\text { intercept }\end{array}$ \\
\hline $\mathrm{BI}_{\text {whole }} \cap \mathrm{MI} 300$ & -40.63 & -315.24 & 5.20 & 1.49 \\
\hline $\mathrm{CIS} \cap \mathrm{MI} 300$ & -64.43 & -506.17 & 3.85 & 2.04 \\
\hline $\mathrm{DRL} \cap \mathrm{MI} 300$ & -41.48 & -322.04 & 5.15 & 1.51 \\
\hline $\mathrm{IDD} \cap \mathrm{MI} 300$ & -40.64 & -315.27 & 5.20 & 1.49 \\
\hline $\mathrm{DRL}>38 \cap \mathrm{MI} 300$ & -40.17 & -311.53 & 5.23 & 1.48 \\
\hline $\mathrm{DRL}<38 \cap \mathrm{MI} 300$ & -42.66 & -331.47 & 5.09 & 1.53 \\
\hline $\mathrm{IDD}>38 \cap \mathrm{MI} 300$ & -39.24 & -304.09 & 5.28 & 1.47 \\
\hline IDD $<38 \cap$ MI300 & -45.02 & -350.45 & 4.96 & 1.57 \\
\hline
\end{tabular}

the intersection between the observed regression line and the MWL being the initial water $\delta$ values for the freezing process (Table $1 \mathrm{~b}$ ). The closed system $M / R$ origin hypothesis is accepted for that group of samples if the two slopes are not statistically different. If $S_{\text {obs }}$ is both statistically different from $S_{\mathrm{MWL}}$ and $S_{\mathrm{CS}}$ or if no significant regression line can be drawn for that specific group, then alternatives (b) and (c) in Sect. 4.1.1 and Fig. 6 have to be considered.
Table 1 summarises the observed regression lines for each group of basal ice samples defined in Sect. 3 (and a few other combinations, see below - Table 1a) and the theoretical closed system freezing lines calculated for the various groups (Table 1b). These data are used in the following section to discuss the origin for the various groups, in conjunction with the other available ice properties. 


\subsection{Origin of the ice types}

\subsubsection{Whole basal ice sequence}

Since the whole basal ice sequence displays a stacking of clear ice and debris bands, one could assume that the whole sequence might have resulted from a large-scale $M / R$ process such as a "bulk freezing-on" mechanism (e.g. at transitions from warm to cold bed conditions under the ice sheet) (Weertman, 1961). The corresponding $\delta^{18} \mathrm{O}_{\text {ice }}-\delta \mathrm{D}_{\text {ice }}$ slope for the whole set of basal ice samples $\left(S_{\text {obs }-\mathrm{BI}_{\text {whole }}}=6.48\right.$, Table 1a) is significantly lower $(P$ value $=0)$ than that of the MWL $\left(S_{\mathrm{MWL}}=S_{\mathrm{MI} 300}=8.02\right)$, excluding a meteoric origin for the whole sequence. A closed system $M / R$ origin hypothesis is highly unlikely because $S_{\mathrm{OBS}-\mathrm{BI}_{\text {whole }}}$ is significantly higher $(P$ value $=0.001)$ than the slope computed from the intersection between $S_{\mathrm{obs}-\mathrm{BI}_{\text {whole }}}$ and the MWL, referred as $S_{\mathrm{BI}_{\text {whole }} \cap \mathrm{MI} 300}(=5.20$, Table $1 \mathrm{~b})$. This and the contrasted properties (Figs. 1 to 4 ) within the sequence suggest that it should indeed not be considered as a single refrozen entity, but rather interpreted as a composite signal.

\section{Clear ice with specks}

The slope of the $\delta^{18} \mathrm{O}_{\text {ice }}-\delta \mathrm{D}_{\text {ice }}$ regression line for the CIS samples $\left(S_{\text {obs-CIS }}=7.93\right.$, Fig. 5 and Table 1a) is not significantly lower $(P$ value $=1)$ than the slope of the MWL $\left(S_{\mathrm{MI} 300}=8.02\right)$. This similarity suggests that $M / R$ events at a scale larger than the resolution of the samples $(5 \mathrm{~cm})$ did not occur for this ice type. This is further confirmed by $S_{\text {obs-CIS }}$ being significantly too high $(P$ value $=0)$ compared to the expected $S_{\mathrm{CS}-\mathrm{CIS}}(3.85)$ that would have been developed from melted MI with $\delta$ values $(-64.4 \% o ;-506 \%$ ) at the intersection with the CIS regression line (totally unrealistic value lying well out of the range of the whole NEEM core - Fig. 5).

The rejection of the $M / R$ hypothesis for the CIS samples is coherent with their textural signature. As shown in Fig. 4, the large crystals of the clear ice samples with specks show a typical small girdle around the core axis. This is similar to the recrystallisation fabric described higher up in the core in the Eemian "warm" ice (Montagnat et al., 2014). This "inherited" strain history is not compatible with meltingrefreezing processes that would have reset the signature to smaller grains oriented according to the simple shear stress regime dominating in the deepest layers of the ice sheet (Cuffey and Paterson, 2010; Hooke and Hudleston, 1980).

Despite the fact that the isotopic and textural signature of the CIS samples are in accordance with a meteoric ice origin, they show a very low total gas content (TGC mean value $=1.46 \mathrm{~mL}_{\text {gas }} \mathrm{kg}_{\text {ice }}^{-1}$, ranging from 0.30 to $5.42 \mathrm{~mL}_{\text {gas }} \mathrm{kg}_{\text {ice }}^{-1}$, Fig. 2c) as compared to typical ice sheet meteoric ice values (ca. $90 \mathrm{~mL}_{\text {gas }} \mathrm{kg}_{\text {ice }}^{-1}$ ). This points to mechanical "reworking" close to the ice-bedrock interface. As discussed for the basal ice layer of EPICA Dome C (EDC)
(Tison et al., 2015), an intense migration recrystallisation process in ice close to the pmp results in drastically increased crystal sizes and expulsion of gases and impurities out of the crystal lattice into the intergranular liquid network. As impurities get concentrated within the premelt layer, they are shown to form precipitated aggregates leading to an ice type very similar to our CIS. A major difference is that, in the EDC basal ice, typical meteoric TGC is preserved. Note that the EDC ice core was terminated at least a few tens of metres above the ice-bedrock interface. It is therefore possible that, at NEEM, the CIS has travelled close enough to the icebedrock interface for its TGC to be partially expelled out of the crystal lattice and drained with the intercrystalline interstitial water (premelt) towards the bedrock. This process is thought to result from the hydraulic gradient driven by the density difference between the premelt and the surrounding ice crystals (Rempel, 2002, 2005). Similar facies have been described close to the ice-bedrock interface of high-altitude alpine glaciers ("clear ice" facies - in Hubbard et al., 2000; Tison and Hubbard, 2000) and at the margin of the Greenland ice sheet ("clotted ice" facies in Sugden et al., 1987; "dispersed with clots" facies in Souchez et al., 1988, 1993).

The CIS ice type has preserved its water stable isotope signature and is the meteoric ice the closest to the ice-bedrock interface. It might therefore be considered as a better reference for the meltwater source to potential refrozen ice types, as compared to the whole set of MI300 samples. However, since folding could have brought meteoric ice from higher up in the ice sheet close to the ice-bedrock interface, we will keep the meteoric ice of the bottom $300 \mathrm{~m}$ (MI300 in Table 1a; $S_{\mathrm{MWL}}=8.02$ ) as the potential reference for the input water signature of the melted ice.

\subsection{Debris-rich layers and ice with dispersed debris}

Both the debris weight content ( 0.4 to $23 \%$, Fig. $2 b$ ) and the debris size distribution (Fig. 3), with a characteristic peak in coarser sands, gravels and individual rock pebbles up to $4.5 \mathrm{~cm}$ in diameter, preclude an aeolian origin for the particle load of the DRL and IDD ice types. Indeed, typical individual particle size ranges e.g. at Camp Century Greenland, from 0.04 to $8 \mu \mathrm{m}$ for the aeolian input (Kumai and Langway Jr., 1988). Only ice-bedrock interactions can therefore be held responsible for the incorporation of such large particle sizes in the NEEM basal ice.

These, however, do not have to imply melting-refreezing processes. Several authors (Anderton, 1974; Echelmeyer and Zhongxiang, 1987; Fitzsimons et al., 1999; Tison et al., 1993) have discussed mechanisms for mechanical entrainment of debris in basal ice below the pmp. Basal ice at the NEEM location is at the pmp and phase changes are therefore likely to occur. Furthermore, the geometrical arrangement of the debris layers (with the repetition of small-scale alternation of clear ice and debris layers) is more typical of melting-refreezing processes (laminated facies - see e.g. re- 
Table 2. Expected range of input water $\delta$ values in an open system freezing configuration computed with the observed slope of 6.45 and a range of $A / F$ values from 1 to 10 .

\begin{tabular}{lll}
\hline$A / F$ & $\delta^{18} \mathrm{O}$ & $\delta \mathrm{D}$ \\
\hline 1 & -42.2 & -327 \\
2 & -41.2 & -319 \\
3 & -40.9 & -316 \\
4 & -40.7 & -315 \\
5 & -40.6 & -315 \\
6 & -40.5 & -314 \\
7 & -40.5 & -314 \\
8 & -40.4 & -314 \\
9 & -40.4 & -313 \\
10 & -40.4 & -313 \\
\hline
\end{tabular}

view from Knight, 1997, and Hubbard et al., 2009), "cold" mechanical entrainment generally resulting in a more homogeneously mixed ice/debris facies (the amber cryofacies in Hubbard et al., 2009). Where available, the debris-bearing ice fabrics (Fig. 4, small crystals) also show a single maximum fabric, typical for ice originating in the vicinity of the ice-bedrock interface. There, simple shear dominates, rather than the vertical small girdle resulting from long-term recrystallisation under progressive burying in pure shear regime (Fig. 4, large crystals) close to the pmp. Finally, a maximum difference of $3.5 \%$ is observed between the highest $\delta^{18} \mathrm{O}$ values in the CIS $(-37.9 \%$ ) and the isotopically heavier debris-bearing ice sample $(-34.4 \%$ ). This difference is close to the maximum $3 \%$ enrichment in $\delta^{18} \mathrm{O}$ for oxygen fractionation between ice and water (O'Neil, 1968). It thus provides further support to a $M / R$ origin for that group. Note that the slightly higher range may also result from multiple $M / R$ events over successive small bumps, a process known to produce laminations (Hubbard and Sharp, 1993).

Do the co-isotopic signature of the debris-bearing (DRL + IDD) ice types further support a $M / R$ origin? Figure 5 shows DRL as red triangles and IDD as green squares. Calculating a regression slope for these two groups together (debris-bearing ice in Table 1a, not shown in Fig. 5) gives a slope $\left(S_{\text {obs-DB }}=6.47\right)$ identical to the one of the whole basal ice sequence $\left(S_{\mathrm{obs}-\mathrm{BI}_{\text {whole }}}=6.48\right)$, which is significantly lower than $S_{\text {MI300 }}(8.02)$, and suggesting potential melting-refreezing. The slope is also significantly too high $(P$ value $=0)$ when compared to the one expected for a closed system $M / R\left(S_{\mathrm{CS}-\mathrm{DB}}=5.26\right)$ with $\delta^{18} \mathrm{O}_{\text {res }}$ and $\delta \mathrm{D}_{\text {res }}$ being the intersection of the regression lines of debrisbearing ice and MI300 groups. Regressions through each individual group gives a slightly higher slope for the DRL samples (6.91) and slightly lower slope (6.27) for the IDD samples, still precluding closed system refreezing.

Closer examination of the behaviour of the debris-bearing samples (Fig. 5) suggests that an inflexion point exists in the overall trend between heavier and lighter samples at about
$(-38 \%$ o, $-296 \%$ ), in other words, close to the transition from HT drill samples to rock drill samples (Fig. 2). This is where resistance to drilling penetration reveals a transition to thicker frozen sediments with larger clasts and interstitial clear ice layers of the IDD type (Figs. 1c and 3). Restricting the regression calculation to IDD samples with $\delta^{18} \mathrm{O}>-38.0 \%$ o (i.e. all IDD samples but one within the ice lenses of the frozen sediments in the bottom part of the core) gives an observed slope of 5.62 (Table 1a), which is significantly different $(P$ value $=0.01)$ from $S_{\text {MI300 }}(8.02)$ but not from the theoretical slope $(P$ value $=1)$ calculated using the intersection of the observed regression line with the MWL (5.28, Table 1b). IDD segments within the frozen sediment at the base of the NEEM core typically represent closed system refreezing. Note that the isotopic values of the initial water for these samples $(-39.2 \%$; $-305 \%$ ) still lies in the range of the CIS samples (open blue symbols in Fig. 5).

The DRL samples with $\delta^{18} \mathrm{O}>-38.0 \%$ (6.45, Table 1a) show significant discrepancy with the MWL line but also with the theoretical slope (5.23, Table 1b), ruling out closed system freezing. Since a clear regression line $\left(R^{2}=0.97\right)$ can be drawn through that group of samples, an open system freezing process can be considered, as shown below.

Using Eq. (2) with (a) initial water values at the intersection of the regression of DRL samples $>-38.0 \%$ and MI300 (Table $1 \mathrm{~b}, \delta^{18} \mathrm{O}=-40.2 \%$ o, $\delta \mathrm{D}=-312 \%$ ), (b) the observed slope of 6.45 and (c) varying $A / F$ ratio from 1 (input equals amount of freezing) to 10 (freezing is only $10 \%$ of input), we can reconstruct the range of plausible isotopic values for the input water in the open system hypothesis (Table 2$)$. The expected isotopic range $(-42.2$ to $-40.4 \%$ in $\delta^{18} \mathrm{O},-327$ to $-313 \%$ in $\left.\delta \mathrm{D}\right)$ is slightly below the lightest CIS ice sample $\left(-39.9 \%\right.$ in $\left.\delta^{18} \mathrm{O}\right)$ but still in the range of the values observed within the last $50 \mathrm{~m}$ of MI above the sampled basal ice sequence (Fig. 5).

As underlined in Sect. 3, the geometrical arrangement of the debris layers in the basal ice sequence (Fig. 4) suggests active folding, in accordance with folding reported higher up in the core (Dahl-Jensen et al., 2013). It is therefore likely that folding has also affected the few tens of metres of deep ice above the basal ice layer, providing opportunities for that ice to melt close to the ice-bedrock interface, somewhere upstream of the drill location, and feeding into the water reservoir for the "open system" refreezing of the debris-rich layers.

Both the DRL and the IDD with isotopic values below $(-38.0 ;-296 \%$ ) do not show a slope of their regression line (respectively 7.24 and 7.52, Table $1 \mathrm{~b}$ ) significantly different from that of the MWL (MI300, with $P$ values of respectively 0.1 and 1). This suggests that within the debris-rich HT section of the basal ice sequence containing relatively less debris, mixing processes between the DRL/IDD ice types and the CIS have destroyed the specific co-isotopic $M / R$ signatures, even at the high $(2 \mathrm{~cm})$ sampling resolution for IDD. Several mechanisms have been invoked for these small-scale 
mixing processes between ice and debris close to the icebedrock interface. Boulton (1970) proposed that individual particles or aggregates are incorporated within the flowing ice by undetectable small-scale melting-refreezing events in the subglacial water film. Small-scale mixing higher up in the sequence could also result from tectonic thrusting of DRL or IDD layers into the surrounding CIS layer during a folding event. Such an incorporation process of debris in ice by tectonic thrusting along shear planes oblique to the layering, in the vicinity of a bedrock hummock, has been proposed for several basal ice sequences (e.g. Boulton, 1975; Echelmeyer and Zhongxiang, 1987; Fitzsimons et al., 1999; Tison et al., 1993). More recently, Waller et al. (2000) and Cook et al. (2011) also underlined the potentially important role of tectonic mixing in the generation and metamorphism of basal ice sequences.

To summarise, our co-isotopic investigations show the following: (a) melting-refreezing has been involved in the genesis of the debris-rich layers and the ice with dispersed debris; (b) this original signature only appears at high-resolution sampling $(2 \mathrm{~cm})$ and has only been preserved in the lower rock-drill section of the basal ice sequence; (c) in that case, IDD results from closed system freezing, while an open system freezing is required for DRL samples; and d) that the specific $M / R$ isotopic signature for both DRL and IDD samples is lost through small-scale mixing ( $<5$ to $2 \mathrm{~cm}$ ) in the higher section of the basal ice sequence.

The ice crystallography within the DRL shows small crystals and a near vertical $c$ axes single maximum (Fig. 4), in accordance with dominant simple-shear in the deeper part of the ice sheet. The debris content has prevented recrystallisation processes in these layers, which act as discrete weaker zones for accumulated stress release, preventing the inherited recrystallisation fabric of the surrounding CIS from crystal size reduction. A similar pattern has been described by Tison et al. (1994) in the upper metre of the GRIP core basal ice sequence.

The relatively higher TGC observed in the debris-bearing ice (DRL + IDD) as compared to the CIS (Fig. 3) may reflect the downward expulsion of the air content from the CIS facies and the subsequent enrichment of the subglacial water prone to refreeze, sometimes in closed system configuration (IDD).

\subsection{A scenario for the build-up of the NEEM basal ice sequence}

The mean $\delta^{18} \mathrm{O}$ value of the NEEM basal ice sequence $(-38.4 \%)$ is within the range of the meteoric ice above, intermediate between Holocene and Younger Dryas values. Reconstructing the local mean surface temperature using the Johnsen et al. (1992) relationship $\left(\delta^{18} \mathrm{O}=0.67 T-13.7 \%\right.$ o gives a value of $-36.8^{\circ} \mathrm{C}$, compatible with the existence of an extensive Greenland ice sheet. Previously depicted mixing processes between relict low-altitude ice bodies and a nascent growing ice sheet, such as those invoked for the basal ice at the GRIP location (Souchez et al., 2006; Souchez et al., 1995; Tison et al., 1998), are therefore not applicable for the build-up of the NEEM basal ice sequence. Its origin must instead be interpreted in terms of incorporation processes of bedrock inherited material within englacial ice that occurred under a pre-existing large ice mass. On the basis of the ice types analysis of the previous section and of the relevant literature, we propose a possible mechanism for the construction of the NEEM basal ice layers, as depicted in Fig. 7.

While snow accumulates and compacts under its own weight to become ice, it simultaneously undergoes a dry recrystallisation process due to the increase of pressure according to depth (Alley, 1992). At the NEEM location, ice flows NW along the divide and the original stratigraphy of the deepest layers is shown to be already disturbed by folding at the last glacial-Eemian boundary (2200-2450 m; DahlJensen et al., 2013). Closer to the ice-bedrock interface, and thanks to the increased recrystallisation at temperatures close to the pmp, impurities (including gases) are gathered at crystal boundaries. As described for the deep ice at EPICA Dome C (de Angelis et al., 2013; Tison et al., 2015) increased concentration of atmospheric-borne impurities at the grain boundaries leads to the precipitation of salts and to the aggregation of visible specks. Depending on the amplitude of the bedrock irregularities, gas expelled within the ice premelt layer will be drained off at the interface with the intergranular water as a result of density contrast (Rempel, 2005; Tison et al., 2015). At NEEM this gas loss (clear ice, no specks, Fig. 7, no. 1) precedes the apparition of visible specks. As the latter appear, the CIS (Fig. 7, no. 2) is created, which nonetheless preserves its inherited fabrics (small girdle around the vertical) and original meteoric signature $\left(S_{\mathrm{CIS}}=7.93\right)$, because no large-scale refreezing is involved.

Pressure melting on the stoss side of bedrock hummocks will produce interfacial meltwater that will flow over and within the basal till, eventually entraining fine abrasion products. Following the pressure gradient, this water will refreeze on the lower pressure lee side of the obstacle (Kamb, 1970; Weertman, 1964). This will result in the repetition of millimetric laminations of debris-rich and clear regelation ice layers such as what has been described here as our DRL ice type (dark obliquely hatched layers in Fig. 7).

Our isotopic analyses show that the refreezing process may occur in an open system regime, with meltwater contribution from meteoric ice above the CIS horizon, having reached the bedrock (and partially melted) upstream of the NEEM drilling location. During this open system refreezing, most of the gases remain dissolved into the water reservoir, although the TGC of DRL is slightly higher (2-6 $\mathrm{mL}_{\mathrm{gas}} \mathrm{kg}_{\mathrm{ice}}^{-1}$, Fig. 2c) than in the CIS layer above. The newly formed DRL show a $c$ axis distribution in accordance with the simple shear stress regime dominant at the base of the ice sheet (single maximum fabric), and their texture made 


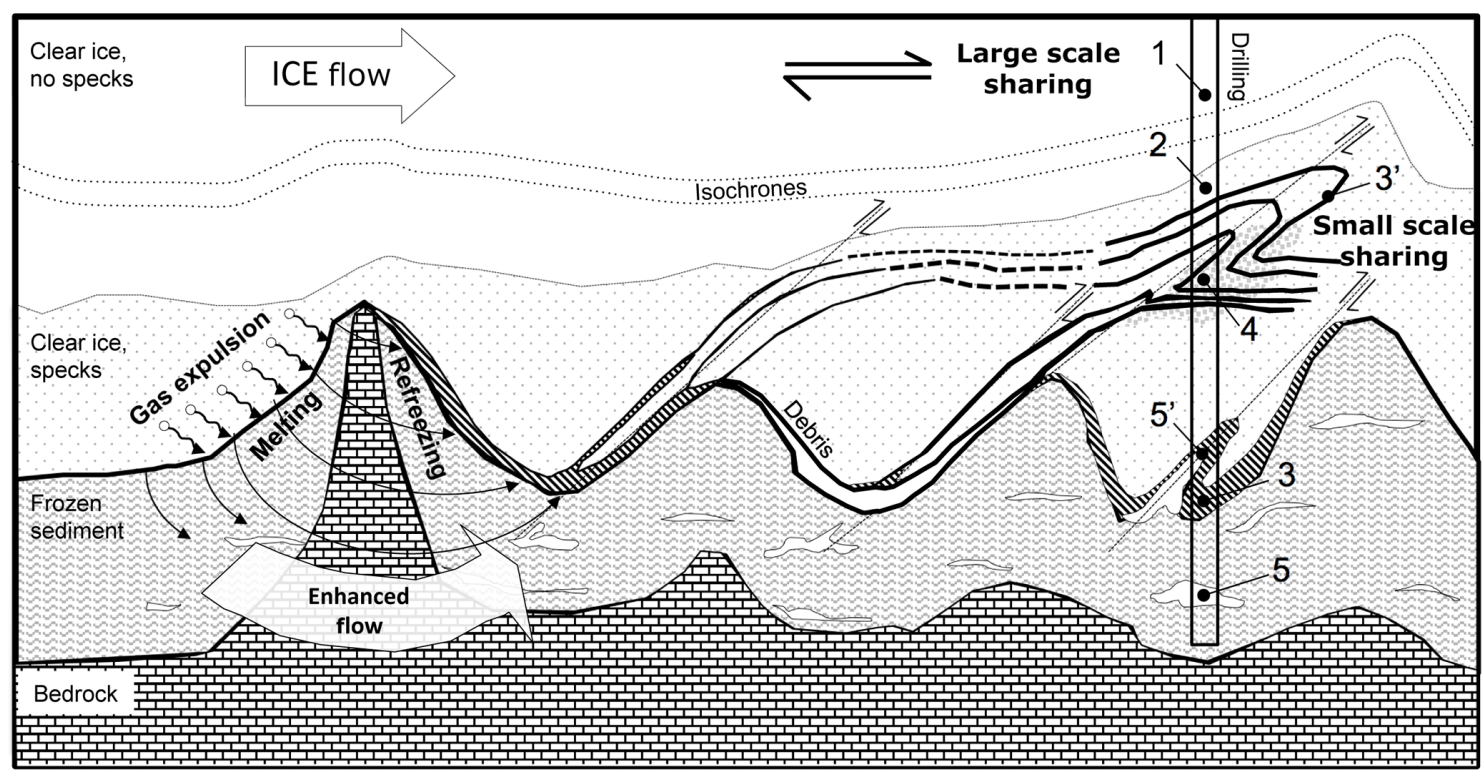

Figure 7. Scheme for the build-up of the basal ice sequence at NEEM, based on the interpretation of the observed properties (not to scale). See text for details. Note that all processes may combine at each bedrock bump. See text for numbers caption.

of small crystals reflects the inhibition of their normal grain growth from the presence of debris (Alley et al., 1986).

While the melting-refreezing DRL have to be formed at the ice-sediment interface, several processes have been proposed to explain their occurrence higher up in the basal ice sequence. For example, it has been suggested that divergent plastic flow on the stoss side of larger bedrock obstacles may entrain pre-existing DRL into the superincumbent ice layers. By repetition of the process, numerous DRL can be intercalated within the CIS, as observed in the top part of our basal ice layer (2533.850 to $2537.300 \mathrm{~m}$ ). Boulton (1970) stated that, in this process, the uppermost debris layers are the first to be incorporated at the farthest point upflow and the lowest debris layers more locally derived. However, the variability and reverse directions of the dip of some of the DRL in our sequence suggest that the latter has been folded. This is consistent with the detailed radio-echo sounding observations of Dahl-Jensen et al. (2013, Fig. S2b and d). Tison et al. (1993) suggest that local shear stress parallel to the local ice-sediment interface, but oblique to the DRL layering, contributes to its protrusion within the ice above and to the development of folds across the layering. This can happen at the interface and help initial incorporation of the DRL (Fig. 7, no. 3) or further up in the sequence with previously incorporated DRL (Fig. 7, no. 3'). This complex deformational regime will result in small-scale mixing with spatial redistribution of the DRL debris within the surrounding CIS, resulting in the formation of clear IDD, with a somewhat blurred co-isotopic signature (Fig. 7, no. 4).

Finally, part of the basal meltwater flowing at the icebedrock interface may progressively infiltrate the pore net- work of the basal till. When the required temperature and pressure conditions are met, the refreezing of that water builds up the isolated layers/lenses of IDD within the frozen sediment, as a kind of segregation ice in permafrost (Fig. 7, no. 5). This ice displays an indisputable closed system $M / R$ origin. When it is formed in closer vicinity of the icesediment interface (Fig. 7, no. 5') it will also dilute its specific isotopic signature within the CIS meteoric signal (Fig. 4, green squares with $\delta^{18} \mathrm{O}<-38.0 \%$ ) as a result of smallscale shearing and/or folding. A TGC of up to $60 \mathrm{~mL}_{\mathrm{gas}} \mathrm{kg}_{\text {ice }}^{-1}$ in the IDD of the lower basal ice section (Fig. 2c) is coherent with a closed system refreezing process, recovering most of the gas content originally expelled from the meteoric ice towards the subglacial water system.

\section{Conclusions}

This multiparametric study of the NEEM basal ice sequence has provided, to our best knowledge, the first opportunity to describe the full transition from unaltered meteoric ice to frozen basal till, including all intermediary stages. Souchez et al. (2000) argued that incorporation of relict ice by overriding during initial ice sheet growth is an important process of basal ice formation in central Greenland. Here, we demonstrate that this situation is not relevant to NEEM, which needs to be interpreted in terms of formation and transformation processes occurring under a well-developed ice sheet. The full sequence involves the following succession on the vertical: (a) clear ice with normal TGC and no specks, (b) clear ice with low TGC and no specks, (c) clear ice with low TGC and specks, (d) laminated debris-rich layers and (e) clear ice with dispersed debris, which can either occur as segregation 
ice within the frozen sediment of the lower part of the sequence or, higher up in the sequence, as a mix between clear ice with specks and lower DRL.

CIS shows large ice crystals, no signs of meltingrefreezing, a pure shear recrystallisation fabric similar to the Eemian ice above and a low debris content with a narrow distribution of silts and fine sands. It can be compared to the EPICA Dome C basal ice sequence (de Angelis et al., 2013; Tison et al., 2015) apart from the fact that it already shows a near complete loss of TGC, suggesting transit closer to bedrock hummocks. Note that EPICA Dome C was stopped some $20 \mathrm{~m}$ above the ice-bedrock interface (Tison et al., 2015). As in EPICA Dome C, the visible specks are homogeneously dispersed into the ice matrix, with increasing number and sizes downwards. Therefore, they most likely represent autochthonous dissolved impurity redistribution at crystal boundaries, with intense recrystallisation and formation of salt precipitates.

With their tail of coarse sands and gravels and total debris content of up to $23 \%$ (similar to those of the basal ice of the Byrd Antarctic core, 12-15\%), DRL and IDD cannot result from aeolian incorporation at the ice sheet surface. This implies thermodynamic (melting-refreezing, coisotopic signature) and/or dynamic (folds, layer dips, single maximum ice fabric) protrusion of basal sediments within the basal ice sequence. This has been described at length in the literature, such as the basal banded series in West Greenland where "stratified facies" (dark laminations of sandy debris and clear ice) are interspersed with "dispersed facies" (clear ice containing fine debris aggregates of silts and clays, also referred to as "clotted ice") segments (e.g. Sugden et al., 1987; Souchez et al., 1993).

Single maximum ice fabrics in the DRL concord with generalized simple shear conditions close to the ice bedrock interface. Melting-refreezing at the ice-bedrock interface of NEEM is coherent with measured temperatures close to the pmp and the upwelling of meltwater in the drill hole on extraction. Finally, gases rejected from the recrystallised meteoric ice above, accumulate within the water-soaked sediment below and can be re-incorporated within the refrozen ice layers, especially if these are formed in a closed system configuration.

Complementary ongoing work within the NEEM basal ice will enable us to further validate and refine the basal ice build-up processes presented here: for example, gas composition and isotopic measurements will highlight potential phase changes and biological fractionation processes, and dating attempts will eventually confirm that the build-up occurred under an already existing and mature ice sheet and help refining the succession of events.

Acknowledgements. We thank all the participants of the NEEM project. NEEM is directed and organised by the Center of Ice and Climate at the Niels Bohr Institute and US NSF Office of Polar
Programs. It is supported by funding agencies and institutions in Belgium (FNRS-CFB and FWO), Canada (NRCan/GSC), China (CAS), Denmark (FIST), France (IPEV, CNRS/INSU, CEA and ANR), Germany (AWI), Iceland (RannIs), Japan (NIPR), Korea (KOPRI), the Netherlands (NWO/ALW), Sweden (VR), Switzerland (SNF), UK (NERC) and the USA (US NSF Office of Polar Programs).

T. Goossens acknowledges support of a FNRS (National Science Foundation, Belgium) FRIA grant $(5.2 .014 .15)$ by the time the present work was conducted. Finally, the authors are very grateful to O. Eisen, P. G. Knight and S. Cook for their supportive and constructive comments on earlier versions of this manuscript.

Edited by: O. Eisen

\section{References}

Alley, R. B.: Flow law hypotheses for ice-sheet modeling, J. Glaciol., 38, 245-256, 1992.

Alley, R. B., Perepezko, J. H., and Bentley, C. R.: Grain growth in polar ice: II. Application, J. Glaciol., 32, 425-433, 1986.

Alley, R. B., Lawson, D. E., Evenson, E. B., Strasser, J. C., Larson, G. J.: Glaciohydraulic supercooling: a freeze-on mechanism to create stratified, debris-rich basal ice: II. Theory, J. Glaciol., 44, 563-569, 1998.

Andersen, K., Azuma, N., and Barnola, J.-M.: Highresolution record of Northern Hemisphere climate extending into the last interglacial period, Nature, 431, 147-151, doi:10.1038/nature02805, 2004.

Anderton, P. W.: Ice fabrics and petrography, Meserve Glacier, Antarctica, J. Glaciol., 13, 285-306, 1974.

Bachmann, F., Hielscher, R., and Schaeben, H.: Texture Analysis with MTEX - Free and Open Source Software Toolbox, Solid St. Phen., 160, 63-68, doi:10.4028/www.scientific.net/SSP.160.63, 2010.

Boulton, G. S.: On the origin and transport of englacial debris in Svalbard glaciers, J. Glaciol., 9, 213-229, 1970.

Boulton, G. S.: Processes and patterns of subglacial sedimentation: a theoretical approach, in Ice Ages: Ancient and Modern, edited by: Wright, A. and Moseley, F., Seel House Press, Liverpool, UK, 7-42, 1975.

Christoffersen, P. and Tulaczyk, S.: Thermodynamics of basal freeze-on: predicting basal and subglacial signatures of stopped ice streams and interstream ridges, Ann. Glaciol., 36, 233-243, 2003.

Christoffersen, P., Tulaczyk, S., Carsey, F. D., and Behar, A. E.: A quantitative framework for interpretation of basal ice facies formed by ice accretion over subglacial sediment, J. Geophys. Res.-Earth, 111, F01017, doi:10.1029/2005JF000363, 2006.

Church, J. A., Clark, P. U., Cazenave, A., Gregory, J. M., Jevrejeva, S., Levermann, A., Merrifield, M. A., Milne, G. A., Nerem, R., Nunn, P. D., Payne, A. J., Pfeffer, W. T., Stammer, D., and Unnikrishnan, A. S.: Sea level change, in Climate Change 2013: The Physical Science Basis. Contribution of Working Group I to the Fifth Assessment Report of the Intergovernmental Panel on Climate Change, 1137-1216, 2013.

Cook, S. J., Knight, P. G., Waller, R. I., Robinson, Z. P., and Adam, W. G.: The geography of basal ice and its relationship to glacio- 
hydraulic supercooling: Svinafellsjökull, southeast Iceland, Quaternary Sci. Rev., 26, 2309-2315, 2007.

Cook, S. J., Robinson, Z. P., Fairchild, I. J., Knight, P. G., Waller, R. I., and Boomer, I.: Role of glaciohydraulic supercooling in the formation of stratified facies basal ice: Svínafellsjökull and Skaftafellsjökull, southeast Iceland, Boreas, 39, 24-38, doi:10.1111/j.1502-3885.2009.00112.x, 2009.

Cook, S. J., Swift, D. A., Darrel, A., Graham, D. J., and Midgley, N. G.: origin and significance of "dispersed facies" basal ice: SVinafellsjökull, Iceland, J. Glaciol., 57, 710-720, 2011.

Craig, H.: Isotopic Variations in Meteoric Waters, Science, 133, 1702-1703, doi:10.1126/science.133.3465.1702, 1961.

Cuffey, K. M. and Paterson, W. S. B.: Grain-Scale Structures and Deformation of Ice, in: The physics of glaciers, Fourth Edition, Elsevier, Burlington, USA, 29-89, 2010.

Dahl-Jensen, D., Albert, M. R., Aldahan, A., et al.: Eemian interglacial reconstructed from a Greenland folded ice core, Nature, 493, 489-494, doi:10.1038/nature11789, 2013.

De Angelis, M., Tison, J. L., Morel-Fourcade, M. C., and Susini, J.: Micro-investigation of EPICA Dome C bottom ice: Evidence of long term in situ processes involving acid-salt interactions, mineral dust, and organic matter, Quaternary Sci. Rev., 78, 248265, doi:10.1016/j.quascirev.2013.08.012, 2013.

Echelmeyer, K. and Zhongxiang, W.: Direct observation of basal sliding and deformation of basal drift at sub-freezing temperatures, J. Glaciol., 33, 83-09, 1987.

Fischer, H., Severinghaus, J., Brook, E., Wolff, E., Albert, M., Alemany, O., Arthern, R., Bentley, C., Blankenship, D., Chappellaz, J., Creyts, T., Dahl-Jensen, D., Dinn, M., Frezzotti, M., Fujita, S., Gallee, H., Hindmarsh, R., Hudspeth, D., Jugie, G., Kawamura, K., Lipenkov, V., Miller, H., Mulvaney, R., Parrenin, F., Pattyn, F., Ritz, C., Schwander, J., Steinhage, D., van Ommen, T., and Wilhelms, F.: Where to find 1.5 million yr old ice for the IPICS "Oldest-Ice" ice core, Clim. Past, 9, 2489-2505, doi:10.5194/cp9-2489-2013, 2013.

Fitzsimons, S. J., McManus, K. J., and Lorrain, R. D.: Structure and strength of basal ice and substrate of a dry-based glacier: evidence for substrate deformation at sub-freezing temperatures, Ann. Glaciol., 28, 236-240, 1999.

Friedman, I., Redfield, A. C., Schoen, B., and Harris, J.: The variation of the deuterium content of natural waters in the hydrologic cycle, Rev. Geophys., 2, 177-224, 1964.

Gow, A. and Meese, D.: Nature of basal debris in the GISP2 and Byrd ice cores and its relevance to bed processes, Ann. Glaciol., 22, 132-140, 1996.

Hooke, R. L. and Hudleston, P. J.: Ice fabrics in a vertical flow plane, Barnes Ice Cap, Canada, J. Glaciol., 25, 195-214, 1980.

Hubbard, B. and Sharp, M.: Basal ice formation and deformation: a review, Prog. Phys. Geog., 13, 529-558, doi:10.1177/030913338901300403, 1989.

Hubbard, B. and Sharp, M.: Weertman regelation, multiple refreezing events and the isotopic evolution of the basal ice layer, J. Glaciol., 39, 275-291, 1993.

Hubbard, B. and Sharp, M.: Basal ice facies and their formation in the Western Alps, Arct. Alpine Res., 27, 301-310, 1995.

Hubbard, B., Tison, J. L., Janssens, L., and Spiro, B.: Ice-core evidence of the thickness and character of clear-facies basal ice: Glacier de Tsanfleuron, Switzerland, J. Glaciol., 46, 140-150, doi:10.3189/172756500781833250, 2000.
Hubbard, B., Cook, S., and Coulson, H.: Basal ice facies: a review and unifying approach, Quaternary Sci. Rev., 28, 1956-1969, doi:10.1016/j.quascirev.2009.03.005, 2009.

Iverson R., N. and Souchez, R.: Isotopic signature of debris-rich ice formed by regelation into a subglacial sediment bed, Geophys. Res. Lett., 23, 1151-1154, doi:10.1029/96GL01073, 1996.

Johnsen, S. J., Clausen, H. B., Dansgaard, W., Fuhrer, K., Gundestrup, N., Hammer, C. U., Iversen, P., Jouzel, J., Stauffer, B., and Steffensen, J. P.: Irregular glacial interstadials recorded in a new Greenland ice core, Nature, 359, 311-313, 1992.

Johnsen, S. J., Hansen, S. B., Sheldon, S. G., Dahl-Jensen, D., Steffensen, J. P., Augustin, L. J., Journé, P., Alemany, O., Rufli, H., Schwander, J., Azuma, N., Motoyama, H., Popp, T., Talalay, P. G., Thorsteinsson, T., Wilhelms, F. and Zagorodnov, V.: The Hans Tausen drill: Design, performance, further developments and some lessons learned, Ann. Glaciol., 47, 89-98, 2007.

Jouzel, J. and Souchez, R.: Melting-refreezing at the glacier sole and the isotopic composition of the ice, J. Glaciol., 28, 35-42, 1982.

Kamb, B.: Sliding motion of glaciers: theory and observation, Rev. Geophys., 8, 673-728, 1970.

Knight, P.: Stacking of basal debris layers without bulk freezing-on: isotopic evidence from West Greenland, J. Glaciol., 35, 214-216, 1989.

Knight, P. G.: The basal ice layer of glaciers and ice sheets, Quaternary Sci. Rev., 16, 975-993, doi:10.1016/S0277-3791(97)000334, 1997.

Kumai, M. and Langway Jr., C. C.: Electron microscope analysis of aerosols in snow and deep ice cores from Greenland, Isot. Impurities Snow Ice, Ann. Glaciol., 10, 208, 1988.

Landais, A., Dreyfus, G., Capron, E., Pol, K., Loutre, M. F., Raynaud, D., Lipenkov, V. Y., Arnaud, L., Masson-Delmotte, V., Paillard, D., Jouzel, J., and Leuenberger, M.: Towards orbital dating of the EPICA Dome $\mathrm{C}$ ice core using $\delta \mathrm{O}_{2} / \mathrm{N}_{2}$, Clim. Past, 8, 191-203, doi:10.5194/cp-8-191-2012, 2012.

Langway, C. C.: Ice fabrics and the universal stage, SIPRE Tech. Rep., CRELL, Hannover, USA, 62 pp., 1958.

Larson, G. J., Lawson, D. E., Evenson, E. B., Knudsen, Ó., Alley, R. B., and Phanikumar, M. S.: Origin of stratified basal ice in outlet glaciers of Vatnajökull and Öræfajökull, Iceland, Boreas, 39, 457-470, doi:10.1111/j.1502-3885.2009.00134.x, 2010.

Lawson, D. E., Strasser, J. C., Evenson, E. B., Alley, R. B., Larson, G. J., and Arcone, S. A.: Glaciohydraulic supercooling: a freezeon mechanism to create stratified, debris-rich basal ice: I. Field evidence, J. Glaciol., 44, 547-562, 1998.

Lehmann, M. and Siegenthaler, U.: Equilibrium oxygen and hydrogen-isotope fractionation between ice and water, J. Glaciol., 37, 23-26, 1991.

Martinerie, P., Lipenkov, V. Y., Raynaud, D., Chappellaz, J., Barkov, N. I., and Lorius, C.: Air content paleo record in the Vostok ice core (Antarctica): A mixed record of climatic and glaciological parameters, J. Geophys. Res., 99, 10565-10576, doi:10.1029/93JD03223, 1994.

Montagnat, M., Azuma, N., Dahl-Jensen, D., Eichler, J., Fujita, S., Gillet-Chaulet, F., Kipfstuhl, S., Samyn, D., Svensson, A., and Weikusat, I.: Fabric along the NEEM ice core, Greenland, and its comparison with GRIP and NGRIP ice cores, The Cryosphere, 8 , 1129-1138, doi:10.5194/tc-8-1129-2014, 2014. 
O'Neil, J. R.: Hydrogen isotope fractionation between ice and water, J. Phys. Chem., 72, 3683-3684, 1968.

Peternell, M., Dierckx, M., Wilson, C. J. L., and Piazolo, S.: Quantification of the microstructural evolution of polycrystalline fabrics using FAME: Application to in situ deformation of ice, J. Struct. Geol., 61, 109-122, doi:10.1016/j.jsg.2013.05.005, 2014.

Raynaud, D., Delmas, D., Ascencio, J. M., and Legrand, M.: Gas extraction from polar ice cores: a critical issue for studying the evolution of atmospheric $\mathrm{CO}_{2}$ and ice-sheet surface elevation, Ann. Glaciol., 3, 265-268, 1983.

Rempel, A.: Englacial phase changes and intergranular flow above subglacial lakes, Ann. Glaciol., 40, 191-194, doi:10.3189/172756405781813564, 2005.

Rempel, A. W.: Anomalous diffusion of multiple impurity species: Predicted implications for the ice core climate records, J. Geophys. Res., 107, 2330, doi:10.1029/2002JB001857, 2002.

Souchez, R. and Jouzel, J.: On the isotopic composition in $\delta \mathrm{D}$ and $\delta^{18} \mathrm{O}$ of water and ice during freezing, J. Glaciol., 30, 369-372, 1984.

Souchez, R., Lemmens, M., Lorrain, R., and Tison, J.-L.: Pressuremelting within a glacier indicated by the chemistry of regelation ice, Nature, 273, 454-456, doi:10.1038/273454a0, 1978.

Souchez, R., Lorrain, R., Tison, J. L., Jouzel, J., Bruxelles, U. L. De, Iouzel, J., and Jouzel, J.: Co-isotopic signature of two mechanisms of basal-ice formation in Arctic outlet glaciers, Ann. Glaciol., 10, 163-166, 1988.

Souchez, R., Lemmens, M., Tison, J.-L., Lorrain, R., and Janssens, L.: Reconstruction of basal boundary conditions at the Greenland Ice Sheet margin from gas composition in the ice, Earth Planet. Sc. Lett., 118, 327-333, doi:10.1016/0012-821X(93)90176-A, 1993.

Souchez, R., Tison, J., Lorrain, R., Lemmens, M., Janssens, L., Stievenard, M., Jouzel, J., Sveinbjörnsdottir, A. and Johnsen, S. J.: Stable isotopes in the basal silty ice preserved in the Greenland Ice Sheet at Summit; environmental implications, Geophys. Res. Lett., 21, 693-696, 1994.

Souchez, R., Lemmens, M., and Chappellaz, J.: Flowinduced mixing in the GRIP basal ice deduced from the $\mathrm{CO}_{2}$ and $\mathrm{CH}_{4}$ records, Geophys. Res. Lett., 22, 41-44, doi:10.1029/94GL02863, 1995.

Souchez, R., Bouzette, A., Clausen, H. B., Johnsen, S. J., Jouzel, J., Clausen B., H., Johnsen J., S., and Jouzel, J.: A stacked mixing sequence at the base of the Dye 3 core, Greenland, Geophys. Res. Lett., 25, 1943-1946, doi:10.1029/98GL01411, 1998.

Souchez, R., Vandenschrick, G., Lorrain, R., and Tison, J.-L.: Basal ice formation and deformation in central Greenland: a review of existing and new ice core data, Geol. Soc. Spec. Publ., 176, 1322, doi:10.1144/GSL.SP.2000.176.01.02, 2000.

Souchez, R., Jouzel, J., Landais, A., Chapellaz, J., Lorrain, R., and Tison, J.-L.: Gas isotopes in ice reveal a vegetated central Greenland during ice sheet invasion, Geophys. Res. Lett., 33, 2-5, doi:10.1029/2006GL028424, 2006.
Souchez, R. A. and De Groote, J. M.: $\delta \mathrm{D}-\delta^{18} \mathrm{O}$ relationships in ice formed by subglacial freezing: paleoclimatic implications, J. Glaciol., 31, 229-232, 1985.

Souchez, R. A. and Lorrain, R. D.: Ice Composition and Glacier Dynamics, Springer Science \& Business Media, Berlin-Heidelberg, Germany, 1991.

Sugden, D. E., Knight, P. G., Livesey, N., Lorrain, R. D., Souchez, R. A., Tison, J.-L., and Jouzel, J.: Evidence for two zones of debris entrainment beneath the Greenland ice sheet, Nature, 328, 238-241, doi:10.1038/328238a0, 1987.

Tison, J., Thorsteinsson, T., Lorrain, R. D., and Kipfstuhl, J.: Origin and development of textures and fabrics in basal ice at Summit, Central Greenland, Earth Planet. Sc. Lett., 125, 421-437, doi:10.1016/0012-821X(94)90230-5, 1994.

Tison, J.-L.: Diamond wire-saw cutting techniques for investigating textures and fabrics of debris-laden ice and brittle ice, J. Glaciol., 40, 410-414, 1994.

Tison, J.-L. and Hubbard, B.: Ice crystallographic evolution at a temperate glacier: Glacier de Tsanfleuron, Switzerland, Geol. Soc. Spec. Publ., 176, 23-38, 2000.

Tison, J.-L., Petit, J.-R., Barnola, J. M., and Mahaney, W.: Debris entrainment at the ice-bedrock interface in sub-freezing temperature conditions (Adélie Land, Antarctica), J. Glaciol., 39, 303 $315,1993$.

Tison, J.-L., Souchez, R., Wolff, E. W., Moore, J. C., Legrand, M. R., and de Angelis, M.: Is a periglacial biota responsible for enhanced dielectric response in basal ice from the Greenland Ice Core Project ice core?, J. Geophys. Res., 103, 18885-18894, doi:10.1029/98JD01107, 1998.

Tison, J.-L., de Angelis, M., Littot, G., Wolff, E., Fischer, H., Hansson, M., Bigler, M., Udisti, R., Wegner, A., Jouzel, J., Stenni, B., Johnsen, S., Masson-Delmotte, V., Landais, A., Lipenkov, V., Loulergue, L., Barnola, J.-M., Petit, J.-R., Delmonte, B., Dreyfus, G., Dahl-Jensen, D., Durand, G., Bereiter, B., Schilt, A., Spahni, R., Pol, K., Lorrain, R., Souchez, R., and Samyn, D.: Retrieving the paleoclimatic signal from the deeper part of the EPICA Dome C ice core, The Cryosphere, 9, 1633-1648, doi:10.5194/tc-9-1633-2015, 2015.

Waller, R. J., Hart, J. K., and Knight, P. G.: The influence of tectonic deformation on facies variability in stratified debris-rich basal ice, Quaternary Sci. Rev., 19, 775-786, 200.

Weertman, J.: Mechanism for the formation of inner moraines found near the edge of cold ice caps and ice sheets, J. Glaciol., 3, 965978, 1961.

Weertman, J.: Glacier sliding, J. Glaciol., 5, 287-303, 1964.

Wilson, C. J. L., Russell-Head, D. S., and Sim, H. M.: The application of an automated fabric analyzer system to the textural evolution of folded ice layers in shear zones, Ann. Glaciol., 37, 7-17, doi:10.3189/172756403781815401, 2003. 